\title{
Revitalisasi Perpustakaan untuk Meningkatkan Minat Literasi Siswa di SD Muhammadiyah Nurul Ilmi, Klaten
}

\author{
Lina Agustina ${ }^{1}$, Arief Arffianto ${ }^{2}$, Salsabila Hasna K. ${ }^{3}$, Lusi Indarwati ${ }^{4}$, Dwindi Roseana Putri ${ }^{5}$, Sheila \\ Erdi El-Majid ${ }^{6}$, Kartina Setia Rahayu ${ }^{7}$, Dicki Yustika Nurleli ${ }^{8}$, Wahyu Agung S. G. ${ }^{9}$, Imroatus \\ Sholihah ${ }^{10}$.

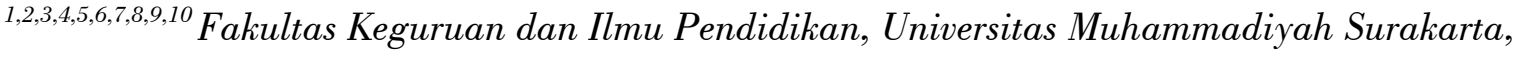 \\ Indonesia
}

\section{INFORMASI ARTIKEL}

\section{Histori Artikel:}

Submit: 27 April 2020

Revisi: 2 Mei 2020

Diterima: 4 Mei 2020

Publikasi: 6 Mei 2020

Periode Terbit: Desember 2019

\section{Kata Kunci:}

minat literasi,

perpustakaan,

revitalisasi,

\section{Correspondent Author:}

Arief Arffianto

Fakultas Keguruan dan Ilmu Pendidikan

Universitas Muhammadiyah Surakarta,

Indonesia

Email: arffiantoarief@gmail.com

\begin{abstract}
ABSTRAK
Salah satu keterampilan yang harus dimiliki di abad 21 ialah keterampilan literasi. Penyediaan bahan bacaan melalui perpustakaan merupakan upaya yang dapat dilakukan sekolah untuk meningkatkan minat literasi siswa. Kegiatan revitalisasi perpustakaan dilaksanakan di SD Muhammadiyah Nurul Ilmi, desa Karangdowo, kecamatan Karangdowo, kabupaten Klaten. Fungsi awal perpustakaan digunakan untuk menyimpan buku SD dan SMP, buku administrasi alat olah raga, peralatan Hizbul Wathan, dan alat peraga pembelajaran. Kondisi yang tidak terawat membuat siswa enggan berkunjung ke perpustakaan. Tujuan yang akan dicapai dalam kegiatan ini ialah mengfungsikan perpustakaan dan meningkatkan minat baca siswa. Tujuan pengabdian ini ialah melaksanakan proses revitalisasi perpustakaan dan meningkatkan minat baca siswa. Metode pengumpulan data dikumpulkan melalui wawancara, observasi, dan dokumentasi. Analisis data dilakukan dengan reduksi data, pemaparan data, dan penarikan kesimpulan. Pengabdian dilakukan dengan tiga tahap, yaitu perencanaan, pelaksanaan, dan pelaporan. Hasil pengabdian ini: 1) Revitalisasi perpustakaan, dilakukan dengan mendekorasi ulang perpustakaan, menyortir buku SMP dan mengklasifikasikan dan melabeli buku, dan membuat buku kunjungan perpustakaan. Berdasarkan klasifikasi, terdapat 156 buku bacaan siswa, 27 ensiklopedia, 314 buku penngetahuan umum, 89 buku guru, dan 814 buku pelajaran KTSP dan kurikulum 2013; 2) Minat baca meningkat dengan rata-rata jumlah siswa yang menginjungi perpustakaan setiap harinya ialah 30 siswa; 3) Perpustakaan difungsikan sebagai tempat alternatif pembelajaran. Dengan demikian, dapat disimpulkan bahwa revitalisasi perpustakaan dapat meningkatkan minat baca siswa dan perpustakaan berfungsi sebagaimana mestinya.
\end{abstract}

\section{Pendahuluan}

Kemajuan peradaban suatu bangsa tidak cukup diukur dari sumber daya alam yang melimpah dan jumlah sumber daya manusia, melainkan kualitas sumber daya manusia. Untuk meningkatkan kualitas tersebut, di abad 21 Indonesia perlu mengembangkan kemampuan literasi. Kemendikbud dalam 
doi: 10.23917/bkkndik.v1i2.10771

(Rahayunintyas \& Yuliyani, 2020) menyatakan bahwa di abad ke-21, masyarakat harus menguasai keterampilan literasi dasar, kompetensi, dan karakter. World Economic Forum pada tahun 2015 menyepakati pentingnya penguasaan literasi (Kemendikbud, 2017). Solikhah dalam (Indriyani, Zaim, Atmazaki, \& Ramadhan, 2019) mendefinisikan literasi sebagai kemampuan membaca dan menulis.

Upaya pengembangan literasi perlu dikembangkan secara terintegrasi, terutama melalui pendidikan. Ini karena, pendidikan memiliki fungsi dan tujuan dalam memajukan peradaban bangsa. Hal ini sejalan dengan tujuan pendidikan nasional, bahwasanya pendidikan bertujuan untuk mengembangkan kemampuan dan membentuk watak serta peradaban bangsa yang bermartabat dalam rangka mencerdaskan kehidupan bangsa (Undang-Undang Republik Indonesia Nomor 20 Tahun 2003 Tentang Sistem Pendidikan Nasional, 2003).

Untuk mengembangkan literasi di Indonesia, pemerintah mengeluarkan Peraturan Menteri Pendidikan dan Kebudayaan RI Nomor 23 Tahun 2015 tentang Penumbuhan Budi Pekerti berisi tentang Kegiatan Gerakan Penumbuhan Budi Pekerti di Sekolah melalui pembiasaan pembiasaan, salah satu kewajiban seorang anak dalam pembelajaran adalah menggunakan 15 menit sebelum hari pembelajaran untuk membaca buku selain buku mata pelajaran (setiap hari) (Permendikbud No.23 tahun 2015). Dalam hal ini, pemerintah menjadikan Sekolah sebagai tempat yang paling awal dari upaya meningkatkan minat baca/literasi. Kegiatan membaca sebagai hal yang wajib dilakukan oleh siswa setiap hari dengan harapan budaya membaca akan menjadi budaya dalam kehidupan mereka.

Sebagai institusi pendidikan formal, sekolah memiliki peran fundamental untuk ikut serta mengembangkan minat literasi siswa. Menurut Effendy dalam (Kemendikbud, 2017), pintu masuk untuk mengembangkan budaya literasi bangsa adalah melalui penyediaan bahan bacaan dan peningkatan minat baca anak. Sayangnya sampai saat ini, minat literasi siswa Indonesia masih rendah. Berdasarkan survei yang dilakukan Central Connecticut State University (CSSU) tentang perilaku literasi, Indonesia berada di posisi ke-61 dari 62 negara. Sedangkan berdasarkan survey yang diadakan Programme for International Student Assesment (PISA), kemampuan baca siswa Indonesia menempati posisi 57 dari 63 negara tahun 2009. (OECD, 2010). Pada tahun 2012 berada pada posisi 64 dari 65 negara (OECD, 2012). Tahun 2015 Indonesia menempati urutan ke-64 dari 72 negara (OECD, 2016). Terakhir pada tahun 2019 Indonesia menempati posisi 72 dari 78 negara peserta survei (OECD, 2018).

Sedangkan data dari Progress in International Reading Literacy Study (PIRLS) dalam bidang membaca pada anak-anak kelas IV sekolah dasar di seluruh dunia di bawah koordinasi The International Association for the Evaluation of Educational Achievement (IEA) yang dikuti 45 negara atau negara bagian, baik berasal dari negara maju maupun dari negara berkembang, hasilnya memperlihatkan bahwa peserta didik Indonesia berada pada peringkat ke 41 yang dilakukan objek pengabdian minat baca dan menulis (PIRLS, 2011)

Senada dengan itu, UNESCO menyebutkan bahwa minat baca masyarakat Indonesia hanya 0,001. Ini berarti hanya 1 dari 
1000 orang Indonesia yang rajin membaca. Dengan demikian, perlu adanya usaha nyata dari berbagai pihak untuk membantuk meningkatkan minat literasi siswa. Salah satunya ialah dengan menjadikan perpustakaan sekolah sebagai pusat meningkatkan literasi siswa. Damayanti dalam (Setyowati \& Erdan, 2018) menyatakan perpustakaan adalah pusat informasi dimana didalamnya bayak tersedia buku dan berbagai jenis referensi yang dibutuhkan untuk memperkuat keilmuan. Oleh karenanya, perpustakaan memiliki fungsi untuk menciptakan masyarakat yang berliterasi. Hal ini sesuai dengan Adianto (2011), bahwa untuk meningkatkan budaya literasi atau minat baca siswa di lingkungan sekolah perlu perhatian khusus dan layanan perpustakaan yang memadai. Sayangnya belum semua sekolah memiliki sarana-prasarana yang memadai, salah satunya perpustakaan.

Sebagai sekolah yang baru berdiri selama delapan tahun, SD Muhammadiyah Nurul Ilmi belum memfungsikan perpusatakaan secara maksimal. Berdasarkan wawancara kepada kepala sekolah dan guru-guru, belum berfungsinya perpustakaan dikarenakan tidak adanya pengelola perpustakaan. Dulunya, sekolah tersebut merupakan SMP Muhammadiyah 12 Karangdowo. Buku-buku koleksi SD masih bercampur dengan buku-buku dan administrasi SMP, serta ruangan perpustakaan masih digunakan untuk menyimpan peralatan olah raga dan alat-alat kegiatan Hizbul Wathan. Dengan keadaan yang demikian, selama delapan tahun perpustakaan belum digunakan. Ini tentunya menyulitkan sekolah untuk meningkatkan minat literasi siswa.
Perlu disadari berbagai pihak, bahwa upaya meningkatkan literasi harus dilakukan secara terintegrasi. Artinya tidak hanya sekolah yang berperan, tapi juga orangtua hingga masyarakat. Lebih spesifik, kewajiban untuk meningkatkan minat baca masyarakat diatur dalam Undang-undang Nomor 43 Tahun 2007 tentang Perpustakaan. Dalam undang-undang tersebut dijelaskan bahwa, meningkatkan minat baca perlu sinergi antara pemerintah dan masyarakat. Berdasarkan kondisi dan uraian tersebut, tim KKN-Dik UMS di desa Karangdowo kabupaten Klaten, tertarik untuk meningkatkan minat literasi siswa SD Muhammadiyah Nurul Ilmi. Upaya yang dilakukan ialah dengan melakukan revitalisasi perpustakaan SD Muhammadiyah Nurul Ilmi.

Tujuan pengabdian ini untuk mendeskripsikan proses revitalisasi perpustakaan dan peningkatan minat literasi siswa SD Muhammdiyah Nurul Ilmi.

\section{Metode Pelaksanaan}

Metode yang digunakan dalam pengabdian ini adalah kualitatif. Teknik pengumpulan data menggunakan wawancara, observasi, dan dokumentasi. Wawancara dilakukan untuk mendapatkan informasi mengenai permasalahan yang dihadapi sekolah dalam mengelola perpustakaan. Observasi dilakukan untuk melihat keadaan perpustakaan mengetahui ketersediaan buku, seperti jumlah buku, jenis bacaan, dan kondisi perpustakaan. Dokumentasi dikumpulkan dari foto dan video sebelum dan sesudah dilakukan revitalisasi perpustakaan.

Pengabdian dilakukan di SD Muhammadiyah Nurul Ilmi yang beralamat di dukuh Kalitengah RT 01 RW 01, desa Karangdowo, kecamatan Karangdowo, 
kabupaten Klaten. Revitalisasi perpustakaan dilaksanakan selama dua minggu yang dibagi dalam tiga tahap, yaitu tahap perencanaan, pelaksanaan, dan pelaporan. Pada tahap persiapan pengabdi melakukan wawancara kepada kepala sekolah dan guru serta observasi ke perpustakaan SD Muhammadiyah Nurul Ilmi. Wawancara dilakukan untuk memperoleh informasi mengenai masalah yang dihadapi sekolah dalam mengelola perpustkakaan dan untuk merencanakan solusi sesuai yang dibutuhkan sekolah.

Tahap pelaksaan program dilakukan pengabdi dengan membuka donasi buku dari pihak luar, mengelompokkan buku-buku berdasarkan jenisnya, memberikan label buku, membuat buku kunjungan perpustakaan, dan mendekorasi ulang perpustakaan. Peningkatan literasi siswa diukur dari jumlah kunjungan siswa ke perpustakaan. Pada tahap pelaporan, pengabdi menyusun artikel ilmiah sebagai laporan kegiatan.

\section{Hasil Pelaksanaan dan Pembahasan}

Hasil kegiatan ini dibagi menjadi dua, yakni proses revitalisasi perpustakaan dan peningkatan minat literasi siswa. Kegiatan tersebut dijabarkan sebagai berikut.

Tahap Perencanaan

Pada tahap ini tim KKN-Dik UMS melakukan wawancara dengan informan kepala sekolah dan guru-guru SD Muhammdiyah Nurul Ilmi serta observasi sebagai pendahuluan. Berdasarkan hasil wawancara, diperoleh informasi bahwa perpustakaan belum difungsikan dari awal berdirinya sekolah. Awalnya sekolah ini merupakan SMP Muhammadiyah 12 Karangdowo, sehingga buku-buku SD masih bercampur dengan buku, administrasi, dan alat peraga pembelajaran SMP. Selain itu, belum ada staf khusus pengelola perpustakaan. Selama observasi dilakukan, perpustakaan belum tersusun rapi. Selain itu, ruangan juga masih digunakan untuk menyimpan alat-alat olah raga dan perlengkapan Hizbul Wathan.

Oleh karena itu, diperoleh kesimpulan bahwa perlu adanya perhatian pada perpustakaan SD Muhammdiyah Nurul Ilmi dengan melakukan revitaslisasi perpustakaan. Revitalisasi difokuskan untuk mendekorasi ulang perpustakaan, menambah koleksi, dan menyusun buku-buku sesuai jenisnya. Rencana revitalisasi selanjutnya dikonsultasikan dengan kepala sekolah, guru, dan Dosen Pembimbing Lapangan (DPL) KKN-Dik.

\section{Tahap Pelaksanaan Program}

Program mulai dilaksanakan pada tanggal 24 Januari 2020. Tahap pelaksanaan dimulai dengan membuka donasi buku dari pihak luar serta membuat proposal untuk memperoleh dana yang digunakan untuk kegiatan. Selain itu dana dikumpulkan dari iuran mandiri tim KKN-Dik. Dana digunakan untuk membeli kertas HVS, solasi, cat tembok, lem fox, kuas, tempat cat, roll untuk mengecat, tinner, dan amplas. Revitalisasi yang dilakukan oleh tim KKN-Dik untuk mengelola perpustakaan antara lain: 1) membersihkan perpustakaan, 2) mendekorasi ulang perpustakaan, 3) menyortir administrasi SMP, 4) memisahkan buku-buku SD dan SMP, 5) mengepak administrasi dan buku SMP yang tidak digunakan 6) mengelompokkan buku sesuai jenis dan melabeli buku, 7) membuat buku kunjungan perpustakaan. Klasifikasi dan jumlah buku disusun sesuai Tabel 1 .

Tabel 1. Klasifikasi dan Jumlah Buku Perpustakaan

\begin{tabular}{ll}
\hline Jenis Buku & Jumlah \\
\hline Buku Guru & 89 buku \\
Buku Bacaan Siswa & 156 buku \\
Buku Pelajaran KTSP \& Kurikulum 814 buku \\
2013 & \\
Buku Pengetahuan Umum & 314 buku \\
Ensiklopedia & 27 buku \\
\hline
\end{tabular}


Setelah diklasifikasikan dan diberikan label, terdapat 89 buku guru, 156 buku bacaan siswa, 814 buku pelajaran KTSP dan kurikulum 2013, 314 buku pengetahuan umum, dan 27 ensiklopedia.

Kondisi perpustakaan sebelum direvitalisasi dapat dilihat pada Gambar 1.

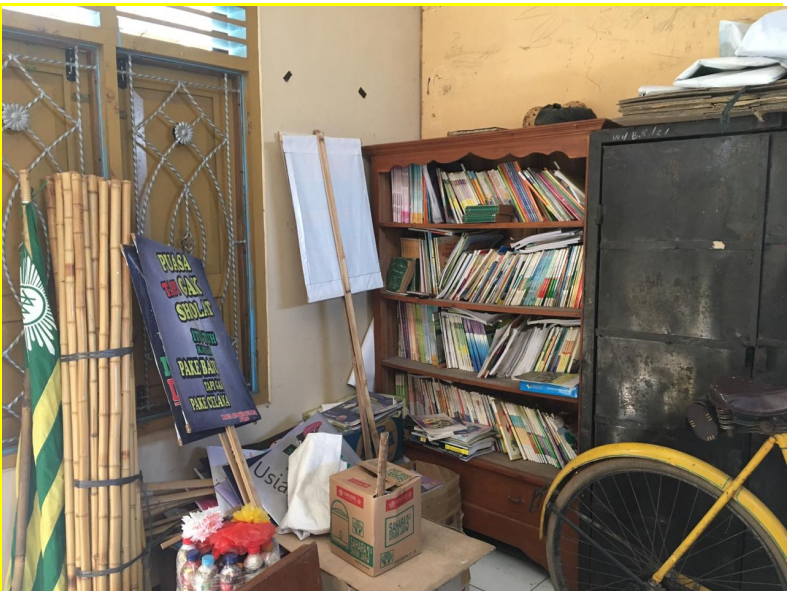

Gambar 1. Kondisi Perpustakaan Sebelum Direvitaslisasi

Proses revitalisasi perpusatakaan oleh Tim KKN-Dik UMS 2020 dapat dilihat pada Gambar 2.

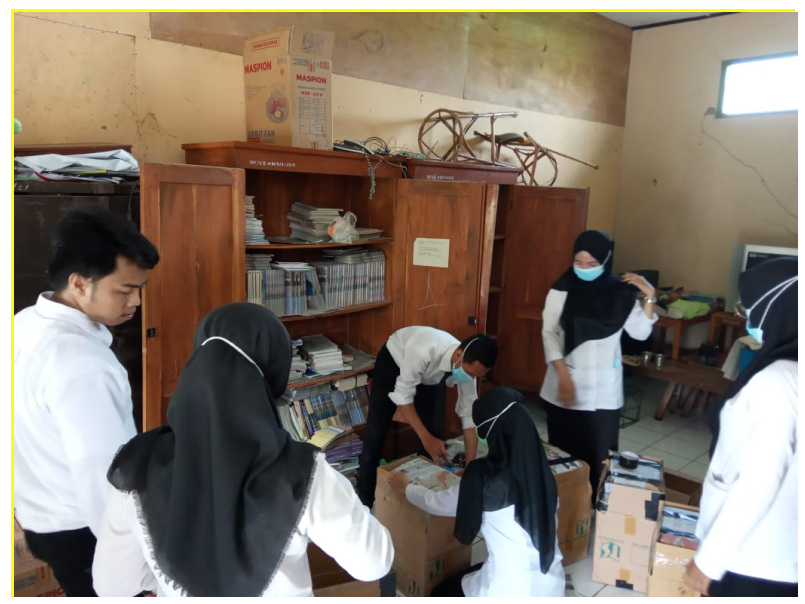

Gambar 2. Kegiatan Revitalisasi Perpustakaan

Selanjutnya, hasil revitaliasi perpustakaan

SD Muhammadiyah Nurul Ilmi disajikan pada Gambar 3, 4, dan 5.

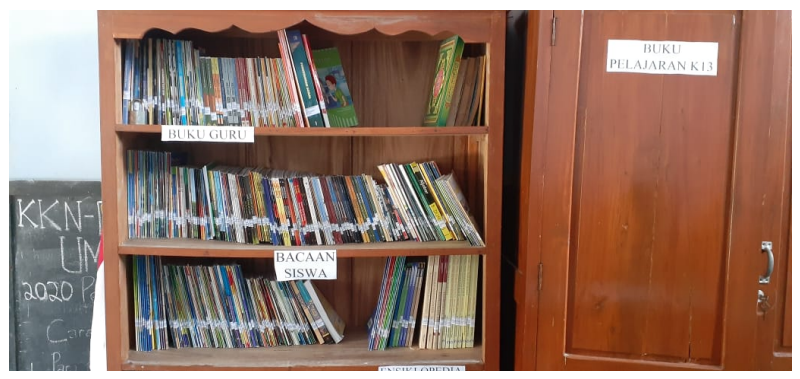

Gambar 3. Susunan Koleksi Buku
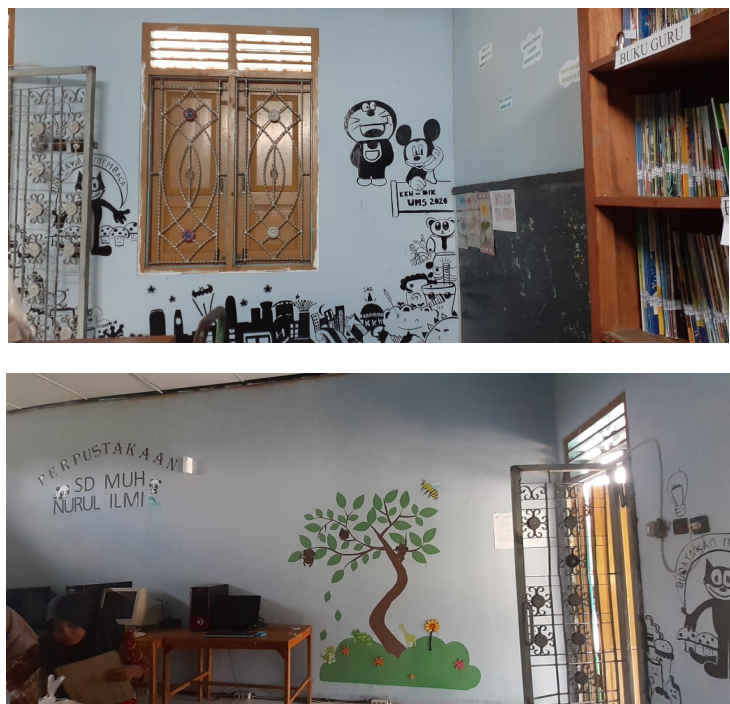

Gambar 4. Perpustakaan Setelah Revitalisasi

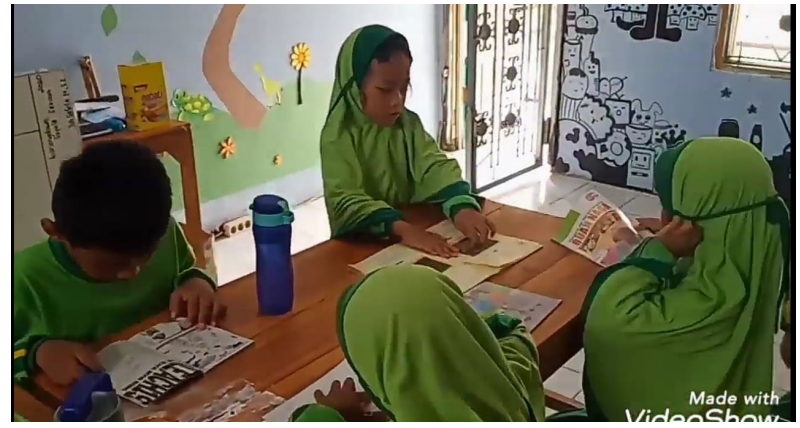

Gambar 5. Aktivitas Membaca Siswa

Berdasarkan gambar revitalisasi perpustakaan di atas, perpustakaan sekolah yang sebelumnya belum difungsikan oleh sekolah, setelah direvitalisasi menjadi lebih rapi dengan buku yang tertata rapi, dekorasi yang bagus dilengkapi dengan buku kunjungan diharapkan akan meningkatkan minat siswa untuk membaca, sehingga siswa dapat memperoleh informasi yang lebih banyak. Hal ini sesuai dengan 
doi: 10.23917/bkkndik.v1i2.10771

Ibrahim Bafadal (2005:3) yang menjelaskan bahwa perpustakaan adalah suatu unit kerja dari suatu badan atau lembaga tertentu yang mengelola bahan-bahan pustaka, baik berupa bukubuku maupun bukan berupa buku (non-book material) yang diatur secara sistematis menurut aturan tertentu sehingga dapat digunakan sebagai sumber informasi oleh setiap pemakainya.

\section{Peningkatan Minat Literasi}

Minat literasi siswa meningkat, dilihat berdasarkan jumlah kunjungan siswa ke perpustakaan setiap harinya. Rata-rata jumlah siswa yang mengunjungi perpustakaan setiap harinya ialah 30 siswa. Jumlah kunjungan sebelum dan sesudah revitalisasi perpustakaan perpustakaan disajikan dalam grafik pada Gambar 6.

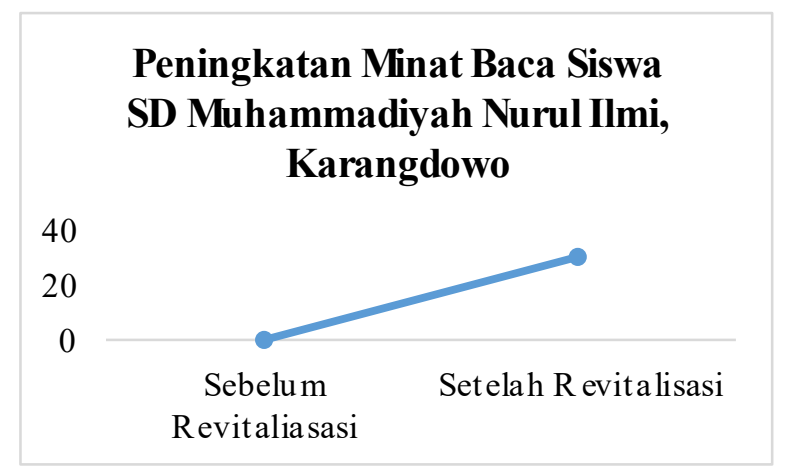

Gambar 6. Grafik Peningkatan Minat Baca Siswa

Selain itu, kegiatan kunjungan perpustakaan siswa disajikan pada Gambar 7 .

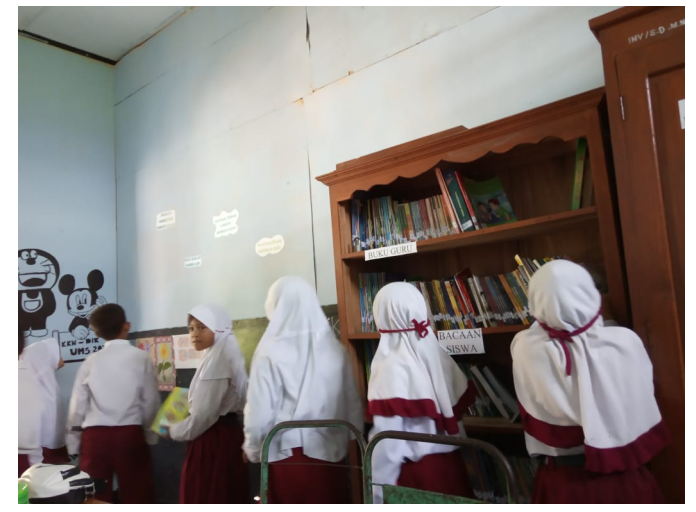

Gambar 7. Siswa Meminjam Buku di Perpustakaan
Selain meningkatkan minat literasi, perpustakaan juga telah difungsikan oleh guru sebagai tempat pelaksanaan pembelajaran. Hal ini dilakukan agar siswa tidak jenuh apabila selalu belajar di dalam kelas.

Meningkatnya minat literasi siswa akan mendorong siswa untuk selalu mengikuti perkembangan informasi. Dengan informasi tersebut siswa akan dapat mengikuti perkembangan zaman, semakin kreatif dan mandiri dalam menangani masalah dalam kehidupannya.

Hal ini sejalan dengan Rohman (2017), yang menyatakan bahwa dengan kemampuan membaca yang membudaya dalam diri setiap anak, maka tingkat keberhasilan di sekolah maupun dalam kehidupan di masyarakat akan membuka pelu ang kesuksesan hidup yang lebih baik. Bukan hanya itu kebiasaan membaca juga dapat membentuk karakter seorang anak. Selain itu, dari peraturan pemerintah yang telah dikeluarkan tentang literasi, pemerintah mengharapkan terbentuk karakter yang baik sejak dini. Karakter tersebut berasal dari materi baca yang berisi nilai-nilai budi pekerti, berupa kearifan lokal, nasional, dan global dan disampaikan sesuai tahap perkembangan peserta didik (Wahyuningsih, A., \& Citraningrum, M., 2019). Terobosan penting ini hendaknya melibatkan semua pemangku kepentingan di bidang pendidikan, mulai dari tingkat pusat, provinsi, kabupaten/kota, hingga satuan pendidikan yaitu sekolah. Pelibatan orang tua peserta didik dan masyarakat juga menjadi komponen penting dalam keberhasilan Gerakan Literasi Sekolah (GLS). 


\section{Tahap Pelaporan}

Laporan disusun sesuai sistematika dengan menjabarkan pendahuluan yang berisi latar belakang, tujuan, dan solusi yang ditawarkan. Analisis data dilakukan dari datadata yang diperoleh selama pengabdian. Selanjutnya menuliskan metode pengabdian, hasil, dan potensi keberlanjutan.

Untuk meningkatkan minat literasi siswa secara berkelanjutan, perpustakaan dapat digunakan untuk kegiatan pembelajaran agar bervariasi. Televisi yang terdapat di perpustakaan, juga dapat difungsikan untuk memutar video-video pembelajaran dan film edukasi. Selain itu, petugas khusus pengelola perpustakaan juga diperlukan. Hal ini mengingat perlunya penataan buku perpustakaan secara berkala, pelayanan sirkulasi, dan laporan secara administratif untuk mencatat aktivitas perpustakaan.

Revitalisasi perpustakaan juga telah dilakukan dalam pengabdian sejenis. Menurut Setyowati \& Erdan (2018) dalam pengabdiannya menyimpulkan setelah peremajaan perpustakaan dilakukan di sekolah tempat mengabdi, sejak hari pertama siswa antuasias mengunjungi perpustakaan. Tidak hanya dibaca di ruang perpustakaan, siswa juga membaca di luar ruang perpustakaan dan siswa juga berminat meminjam buku untuk dibaca di rumah. Agar senantiasa berfungsi dengan baik, tim pengabdi juga menyarankan kepada sekolah untuk tetap menjaga kebersihan dan kenyamanan perpustakaan.

Senada dengan itu, Asy'ari (2018) dalam penelitiannya menyimpulkan, bahwa minat baca sebenarnya dapat dilatih. Koleksi buku yang lengkap, pelayanan, dan desain perpustakaan yang baik akan meningkatkan minat baca siswa.
Tentunya desain perpustakaan juga disesuai dengan kebutuhan untuk menunjang kenyamanan dalam membaca.

Pemanfaatan perpustakaan sebagai tempat pembelajaran juga terdapat dalam hasil pengabdian yang sejenis. Zulaikha, Suardiman, \& Kuntoro (2016) dalam pengabdiannya menyimpulkan, guru tertarik menggunakan perpustakaan untuk mendukung pembelajaran. Hal ini tampak dari guru yang melakukan penugasan di perpustakaan, meminjam perpustakaan untuk melaksanaka pembelajaran, dan menjadikan perpustakaan sebagai tempat informasi dalam menambah materi.

\section{Simpulan}

Berdasarkan pengabdian yang dilakukan oleh tim KKN-Dik dapat disimpulkan bahwa revitalisasi perpustakaan yang dilakukan pada SD Muhammadiyah Nurul Ilmi dilakukan dengan efektif dan efisien. Dapat dikatakan efektif dan efisien karena program ini tidak menghabiskan banyak dana, selesai sesuai waktu yang direncakan, dan mencapai tujuan dengan baik. Minat literasi siswa melalui perpustakan meningkat dan tim KKN-Dik telah memfungsikan kembali perpustakaan yang telah lama tidak berfungsi.

Dampak dari revitalisasi tersebut antara lain siswa dapat mengisi waktu luang dengan membaca berbagai jenis buku di perpustakaan dan ruang perpustakaan dapat dijadikan tempat sebagai ruang alih pembelajaran ketika membutuhkan suasana berbeda dalam proses belajar mengajar. Oleh karena itu, perpustakaan menjadi sarana penting yang dapat mendorong dan mengembakan pemikiran siswa menuju pemikiran yang berwawasan luas dan terbuka. 
Penumbuhan Budi Pekerti. (2015). Retrieved from https://ainamulyana.blogspot.com/2015/1 0/download-permendikbud-nomor-23tahun.html.

Progress in International Reading Literacy Study (PIRLS). (2011). Analisis Hasil Belajar Peserta Didik dalam Literasi Membaca melalui Studi Internasional, http://litbang.kemdikbud.go.id/index.php/ survei-internasional-pirlsl/ laporan-pirls.

Rahayunintyas, D. I., \& Yuliyani, D. R. (2020). Pengembangan Model Multiple Intelligences Based Learning Untuk Penguatan Gerakan Literasi Sekolah Dasar Kelas Tinggi. Jurnal Cakrawala Pendas, 6(1), 63-74. https://doi.org/http://dx.doi.org./10.31949/ jep.v6il.1698.

Rohman, Syaifur. (2017). Membangun Budaya Membaca Pada Anak Melalui Program Gerakan Literasi Sekolah. Terampil: Jurnal Pendidikan dan Pembelajaran Dasar, 4(1), 151-174.

Setyowati, L., \& Erdan, W. (2018). Menumbuhkan Budaya Literasi Melalui Gerakan "Ayo Membaca Buku" di Perpustakaan MTs Assalam Pasuruan. Jurnal Vokasindo, 6(2), 100-112. Retrieved from https://vokasindo.ub.ac.id/index.php/voka sindo/article/view/96.

Undang-Undang Republik Indonesia Nomor 20 Tahun 2003 Tentang Sistem Pendidikan Nasional. (2003).

Undang-Undang Republik Indonesia Nomor 20 Tahun 2003 Tentang Sistem Pendidikan Nasional. (2003).

OECD. (2016). Country note - results from PISA 2015: Indonesia. https://doi.org/http://dx.doi.org/10.1787/8 88933431961.

OECD. (2018). Insights and interpretations. https://doi.org/https://doi.org/10.1787/5fo 7c754-en.

Permendikbud Nomor 23 Tahun 2015 tentang uningsih, A., \& Citraningrum, M. (2019). The Effectiveness of The Cooperative Integrated Reading and Composition (CIRC) and Preview Question Read Reflect Recite Review (PQ4R) on Reading Comphrehension Skill. Indonesian Journal on Learning and 
Advanced Education (IJOLAE), 1(1), 2636.

Warsihna, Jaka. (2016). Meningkatkan Literasi Membaca Dan Menulis Dengan Teknologi Informasi Dan Komunikasi (Tik). Kwangsan, 4(2), 67-80.

Zulaikha, S. R., Suardiman, S. P., \& Kuntoro, S. A. (2016). Pengembangan Model
Perpustakaan Madrasah Dalam Penerapan Literasi Informasi Untuk Mempersiapkan Belajar Sepanjang Hayat. Jurnal Pembangunan Pendidikan: Fondasi Dan Aplikasi, $\quad 3(2), \quad 213-224$. https://doi.org/10.21831/jppfa.v3i2.9812. 